\title{
Greywater impact on green roofs' provision of ecosystem services
}

Article

Accepted Version

Kemp, S., Blanusa, T. and Hadley, P. (2017) Greywater impact on green roofs' provision of ecosystem services. Acta Horticulturae, 1189 (103). pp. 513-518. ISSN 0567-7572 doi: https://doi.org/10.17660/ActaHortic.2017.1189.103 Available at https://centaur.reading.ac.uk/75424/

It is advisable to refer to the publisher's version if you intend to cite from the work. See Guidance on citing.

Identification Number/DOI: https://doi.org/10.17660/ActaHortic.2017.1189.103 <https://doi.org/10.17660/ActaHortic.2017.1189.103>

Publisher: International Society for Horticultural Science

All outputs in CentAUR are protected by Intellectual Property Rights law, including copyright law. Copyright and IPR is retained by the creators or other copyright holders. Terms and conditions for use of this material are defined in the End User Agreement.

www.reading.ac.uk/centaur

\section{CentAUR}

Central Archive at the University of Reading 
Reading's research outputs online 


\title{
Greywater impact on green roofs' provision of ecosystem services
}

\author{
S. Kemp ${ }^{1, a}$, T. Blanuša ${ }^{1,2}$ and P. Hadley ${ }^{1}$ \\ ${ }^{1}$ School of Agriculture, Policy and Development, University of Reading, UK; ${ }^{2}$ Royal Horticultural Society, UK
}

\begin{abstract}
Previous research showed that some herbaceous perennial species could offer summertime cooling better than succulent species on green roofs (GRs), if supplementary irrigation is available during times of drought. In light of increasing water shortages, use of greywater (GW) instead of mains tap water (TW) for this purpose comes into focus. A glasshouse experiment was conducted in summer 2015 at the University of Reading (UK) to assess the impact of GW irrigation on the health, growth and functioning (in terms of leaf stomatal conductance $\left(g_{s}\right)$ and associated water uptake) of four plant genotypes (Salvia, Stachys, Heuchera and Sedum), and their ability to deliver ecosystem services, particularly cooling. Twenty-two replicates of each genotype, plus controls of bare, unvegetated substrate, were irrigated with fixed volumes of TW or synthetic GW for 6 weeks. Plant growth and visual quality, and $g_{s}$ were measured. In Week 7 , daily water loss from each container following saturation was determined. For the first 6 weeks, plant growth, visual quality and $g_{s}$ were similar for both TW and GW treatments for all genotypes, indicating no negative impact of short-term GW irrigation and no apparent impact on cooling when plants were well-watered. However, in Week 7 water uptake (and thus presumably $g_{s}$ ) was significantly lower for plants irrigated with GW compared to TW for some genotypes (Salvia and Heuchera), especially as substrate became drier, suggesting a reduction in evapotranspiration and potentially reduced cooling service when the soil is dry.
\end{abstract}

Keywords: Salvia, Stachys, Heuchera, Sedum, sustainable irrigation, cooling, water uptake

\section{INTRODUCTION}

Green roofs (GRs) have the potential to provide multiple ecosystem services (ESs), including surface and aerial cooling and stormwater management. Recent studies have shown that a variety of species with different morphological and physiological characteristics than traditionally used succulent species (e.g. Sedum sp.) may be able to provide ESs at a higher degree (Blanusa et al., 2013; Vaz Monteiro et al., 2016). However, it is also apparent that, since plants have been found to provide cooling mainly through evapotranspiration (ETp), supplementary irrigation of these species is required during times of drought to ensure plant survival and continued provision of ESs (Blanusa et al., 2013). Water shortages and competition for limited water resources in urban areas are becoming widespread, consequently reducing the availability of water for GR irrigation (Pinto et al., 2010); using greywater (GW) instead of tap water (TW) may therefore provide a sustainable alternative for GR irrigation.

Greywater consists of household wastewater that originates from the kitchen, laundry and bathroom, but excludes black water from the toilet (Eriksson et al., 2002), and has variable quality depending on source within the house, products used by occupants, and so forth (Pinto et al., 2010). When used for irrigation, GW can have negative impacts on soils (e.g. reduction in hydraulic conductivity; Travis et al., 2010) and their ability to support plant growth (Rodda et al., 2011), mainly due to accumulation of salts, surfactants, oils and nutrients in the soil and elevated soil pH (Albalawneh et al., 2016). The impact of GW on plant health and growth varies between species with different tolerances (Sharvelle et al., 2012), and may be either beneficial (acting as a fertiliser and improving plant growth;

a E-mail: s.kemp@pgr.reading.ac.uk 
Rodda et al., 2011) or detrimental (nutrients accumulating in toxic levels and reducing plant growth; Travis et al., 2010). Few studies have investigated the impact of GW on the provision of ESs, and generally consideration has been limited to water uptake and transpiration (e.g. Eriksson et al., 2006; Pinto et al., 2010). Reduced soil hydraulic conductivity may make it more difficult for plants to take up water, potentially limiting transpiration and consequently impacting plants' health and ability to provide ESs such as cooling (Ouldboukhitine et al., 2014).

It is clear that GW has the potential for use in supplementary irrigation of GRs but it is not yet fully understood how plants with high ETp rates and thus good cooling potential will respond to it. The principal objectives of this study, therefore, were to investigate the tolerance of some potential GR genotypes to short-term irrigation with GW (in terms of effects on their health, growth and functioning). Extensive previous research within our group with these genotypes under similar conditions identified plant transpiration as the primary mechanism through which cooling is provided, with $g_{s}$ also closely linked to the plants' cooling potential (Blanusa et al., 2013; Vaz Monteiro et al., 2016; 2017). The impact of GW on continued provision of ESs, particularly cooling, through modification of stomatal conductance and associated ETp was therefore also investigated in this study.

\section{MATERIALS AND METHODS}

\section{Plant material and growing medium}

Three broadleaf perennial genotypes (Salvia officinalis, Stachys byzantina and Heuchera 'Obsidian') that have previously shown potential to provide a good cooling service on GRs (Blanusa et al., 2013; Vaz Monteiro et al., 2016) were tested along with the traditional GR succulent Sedum sp. In April 2015, all genotypes were planted into $2 \mathrm{~L}$ containers (17 cm diameter) with $11 \mathrm{~cm}$ depth of a 50:50 mix of peat-based compost and vermiculite (one plant per container). Heuchera and Sedum were two year old plants, whilst Salvia and Stachys were propagated from cuttings in January 2015. There were 22 replicates of each genotype along with bare, vegetation-free substrate. On Day 0 of the experiment, 4 additional plants of each genotype were harvested to obtain baseline biomass information.

\section{Impact of GW on plant health, growth and function}

The experiment was carried out between $21^{\text {st }}$ May and $13^{\text {th }}$ July 2015 in a ventilated glasshouse on the Whiteknights campus of the University of Reading, UK. For the first 6 weeks, half of the containers were watered with TW and half with GW. Industry standard synthetic GW (Diaper et al., 2008) was used for irrigation to ensure that chemical and physical properties were consistent throughout the experiment. Irrigation volumes were determined from substrate moisture and plant water use tests carried out in March/April 2015 , with the aim of preventing any leachate production whilst also maintaining substrate moisture content (SMC) within the "well-watered" range $\left(>0.25 \mathrm{~m}^{3} \mathrm{~m}^{-3}\right.$; Blanusa et al., 2013 ) to prevent plant stress. TW and GW irrigation volumes were always identical, and water was applied to the soil by hand to avoid direct contact between plant foliage and GW (Misra et al., 2010) 5 times per week.

Leaf stomatal conductance to water vapour $\left(g_{s}\right)$ of all plants was measured on Day 0 (to obtain baseline values) and then once per week using an LCpro-SD infrared gas analyser (ADC BioScientific Ltd., Hoddesdon, UK) except for Sedum, which was measured with an AP4 Porometer (Delta-T Devices, Cambridge, UK) due to small leaf size. Canopy temperatures were also measured on Day 0 and then once per week by analysing thermal images of each plant taken with an infrared imaging camera Thermo Tracer TH7800 (NEC San-ei Instruments Ltd., Tokyo, Japan). Starting from Day 1, SMC and substrate electrical conductivity (EC) of all containers were measured prior to irrigation 3 times per week using a WET sensor connected to a HH2 Moisture Meter (Delta-T Devices, Cambridge, UK). Plant growth (height and diameter) and visual health and quality were measured on Day 1 and then every 2 weeks; quality of each plant was visually assessed using a rating scale from 0 - 
5 based on the rating system used by Sharvelle et al. (2012). At the end of 6 weeks, 10 plants from each treatment ( $5 \mathrm{TW}$ and $5 \mathrm{GW}$ ) were harvested to obtain shoot and root dry weights.

\section{Impact of GW on plant water use after 6 weeks of GW irrigation}

In Week 7 ( $6^{\text {th }}-13^{\text {th }}$ July), the remaining 12 containers per treatment were saturated to container capacity by submerging in either TW or GW as appropriate for 15 minutes and then draining for 1 hour. Containers were weighed after draining and then every 24 hours for a week; no further irrigation was applied in this time.

\section{Statistical analysis}

Statistical analysis was carried out using GenStat $16^{\text {th }}$ edition software (VSN International Ltd., Hemel Hempstead, UK). For each treatment, analysis of Variance (ANOVA) was used to assess the effect of irrigation treatment (TW or GW) on measured parameters. Variance levels were checked for homogeneity and values were reported as means with associated LSDs (least significant difference between the means; $p<0.05$ ).

\section{RESULTS AND DISCUSSION}

\section{Greywater and substrate EC}

Average EC of the synthetic GW mix for the experiment was slightly but statistically significantly higher than the EC of the TW used (599 $\mu \mathrm{S} \mathrm{cm}^{-1}$ compared to $\left.528 \mu \mathrm{S} \mathrm{cm}-1\right)$. Although this was higher than the desired EC range (300-400 $\left.\mu \mathrm{S} \mathrm{cm}^{-1}\right)$ suggested by Diaper et al. (2008), it was substantially lower than the majority of EC values reported in the literature for both synthetic and real GWs, which are frequently over $1000 \mu \mathrm{S} \mathrm{cm}{ }^{-1}$ (e.g. Pinto et al., 2010). During the first 6 weeks, substrate EC of all treatments was generally between 700 and $1500 \mu \mathrm{Sm}^{-1}$ (data not shown), which is within the recommended substrate EC range of $0-1500 \mu \mathrm{S} \mathrm{m}^{-1}$ suggested by De Clerck et al. (2003) for acceptable plant growth and soil microbial activities. Similar to other studies (e.g. Sharvelle et al., 2012), the EC of GW irrigated containers was generally higher than that of TW irrigated containers, and significantly higher by Week 6 for the control, Heuchera and Sedum. Substrate EC for Stachys, however, was similar for both TW and GW irrigated plants throughout the 6 weeks (data not shown), suggesting that salts did not accumulate significantly in the substrate and so any negative effects of GW would be minor for Stachys.
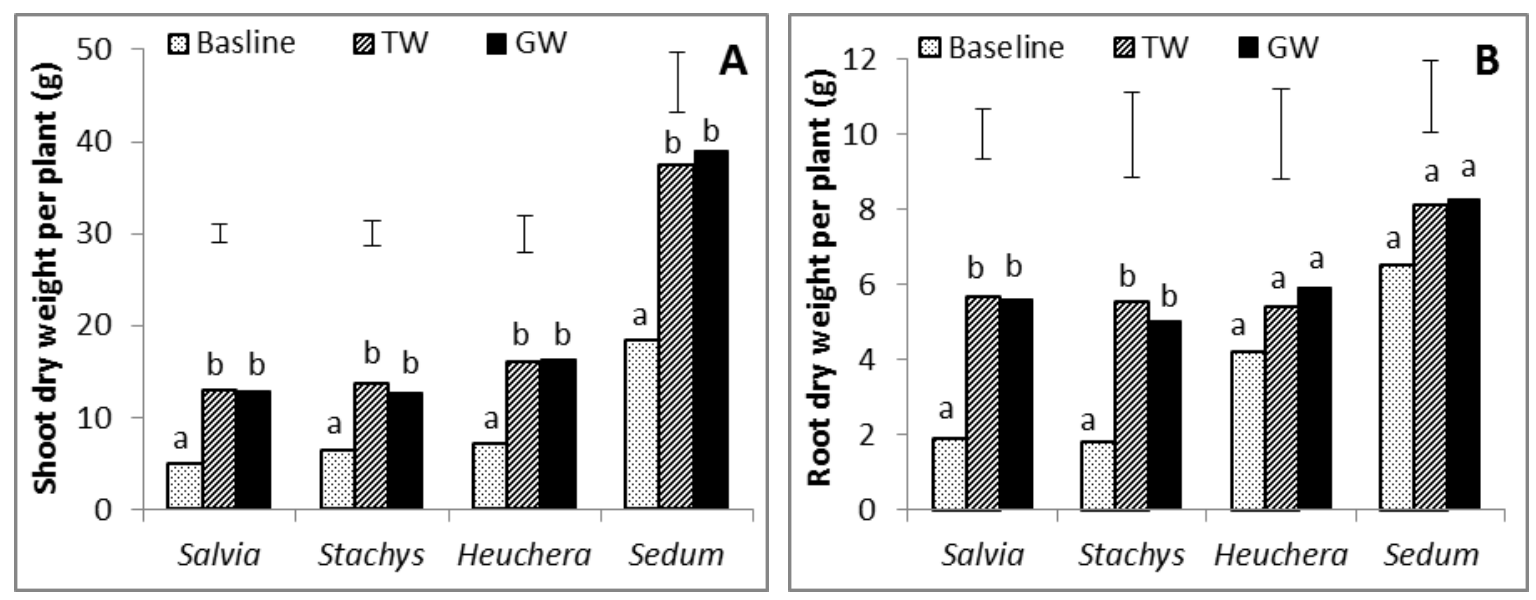

Figure 1. Average shoot (A) and root (B) dry weights for baseline plants and tap water (TW) and grey water (GW) irrigated plants after 6 weeks. Different letters indicate statistical differences between treatments, with associated LSD bars $(\mathrm{p}<0.05)$.

\section{Plant growth and quality}

During the first 6 weeks of the experiment, there were no statistically significant differences between TW and GW treatments in plant height, diameter and visual quality 
(data not shown) for any genotype. Biomass of all genotypes increased over the course of the experiment, but there were no differences in shoot or root dry weights between TW and GW treatments for any genotype (Fig. 1). Results suggest that all genotypes were able to tolerate short-term irrigation with GW with no negative consequence, similar to the results of several other studies (e.g. Pinto et al., 2010).

\section{Stomatal conductance}

Generally there were no statistically significant differences in $g_{s}$ between TW and GW treatments for any of the genotypes for the first 6 weeks (Table 1), the only exceptions being for Sedum at week 4 and Heuchera at week 6, when $g_{s}$ was significantly higher in TW treatments compared to GW. Heuchera baseline $g_{s}$ was very low, possibly as a result of apparent transplanting stress (experience has shown that Heuchera can be sensitive to transplanting and may require a long period to adapt to new substrate); generally Heuchera $g_{s}$ increased over the course of the experiment for both TW and GW treatments, concurrently with an observed improvement in visual quality.

Stachys $g_{s}$ was consistently high throughout the experiment for both TW and GW treatments and in line with published values ( $>200 \mathrm{mmol} \mathrm{m}^{-2} \mathrm{~s}^{-1}$; Blanusa et al., 2013), with no apparent impact of GW on $g_{s}$, which correlates well with Stachys substrate EC. Salvia $g_{s}$ for both TW and GW treatments were high at the start of the experiment but decreased over time, particularly in the last week when it was only $54 \%$ or $61 \%$ of baseline $g_{s}$ for TW and GW treatments respectively. This appears to have suppressed the $g_{s}$ of both TW and GW irrigated plants to the same extent and was probably connected to an observed decline in the visual health and quality of all Salvia plants in the latter half of the experiment.

Table 1. Average leaf stomatal conductance $\left(g_{s}\right)$ of each genotype under tap water (TW) and greywater (GW) irrigation regimes over the course of the experiment. Differences in mean $g_{s}$ between TW and GW plants of each genotype each week of the experiment were only statistically significant $(\mathrm{p}<0.05)$ where results are bold (LSD = 21.7 for Heuchera in Week 6 and 17.09 for Sedum in Week 4).

\begin{tabular}{lcccccccc}
\hline \multirow{2}{*}{ Time } & \multicolumn{8}{c}{ Mean leaf stomatal conductance $\left(\mathbf{m m o l ~ m}^{-\mathbf{2}} \mathbf{s}^{-1}\right)$} \\
\cline { 2 - 9 } & \multicolumn{3}{c}{ Salvia } & \multicolumn{2}{c}{ Stachys } & Heuchera & \multicolumn{2}{c}{ Sedum } \\
\hline & TW & GW & TW & GW & TW & GW & TW & GW \\
\hline Baseline & 267 & 277 & 225 & 239 & 32 & 50 & 111 & 120 \\
Week 1 & 275 & 282 & 234 & 247 & 50 & 62 & 22 & 21 \\
Week 2 & 290 & 296 & 268 & 256 & 78 & 89 & 64 & 53 \\
Week 3 & 264 & 249 & 243 & 255 & 91 & 76 & 36 & 18 \\
Week 4 & 247 & 262 & 231 & 254 & 94 & 75 & $\mathbf{3 8}$ & $\mathbf{2 0}$ \\
Week 5 & 238 & 237 & 229 & 250 & 88 & 82 & 29 & 17 \\
Week 6 & 144 & 168 & 203 & 218 & $\mathbf{8 3}$ & $\mathbf{6 0}$ & 14 & 10 \\
\hline
\end{tabular}

Contrary to results of other studies (e.g. Eriksson et al., 2006), $g_{s}$ in this study generally was not suppressed by GW irrigation whilst plants were kept well-watered (typically $>0.200 \mathrm{~m}^{3} \mathrm{~m}^{-3}$; data not shown). Additionally, there were no differences in the canopy temperatures of TW and GW irrigated plants within all genotypes at any time throughout the study (data not shown). Since high $g_{s}$ has proven to be a key trait for providing cooling with these genotypes (Vaz Monteiro et al., 2017), results suggest that the extent of the cooling service provided would not be compromised by irrigation with GW.

\section{Impact of GW on plant water use after 6 weeks of GW irrigation}

In the final week of the experiment, there was a general trend of lower water uptake by the plants in the GW treatments than in the TW treatments for some genotypes (Heuchera and Salvia) and the control (Table 2); there were no significant differences for Stachys or Sedum (data not shown). This correlates well with the other results in this experiment $\left(g_{s}\right.$, plant growth, substrate EC) which have also indicated that Stachys appears to be tolerant to GW irrigation, at least in the short-term, and is similar to results of other 
studies (e.g. Misra et al., 2010), which also report no difference in water uptake between TW and GW treatments. It is likely that for Stachys and probably Sedum, ETp in the TW and GW treatments remained similar through the drying period (hence resulting in similar water uptake). This suggests that the cooling service provided by the plants would not have been compromised by GW irrigation, as transpiration has previously been identified as the primary mechanism for cooling provision with these genotypes (Blanusa et al., 2013; Vaz Monteiro et al., 2017). Conversely, water uptake from plants irrigated with GW compared to TW was significantly lower for almost the whole experiment for Heuchera and significantly lower towards the end of the week for Control and Salvia (Table 2). This contrasts with the results of Sharvelle et al. (2012), who reported significantly higher water uptake by plants irrigated with GW than by plants irrigated with TW, although this was partly attributed to greater growth of the GW irrigated plants, which was not the case in this study. Lower water uptake from Heuchera irrigated with GW compared to TW corresponds to the reduced $g_{s}$ for the GW irrigated plants measured in Week 6, indicating a likely reduction in the cooling potential of Heuchera at this time (Vaz Monteiro et al., 2017).

Table 2. Average cumulative water loss per container in the week following saturation for the control, Salvia and Heuchera under tap water (TW) and greywater (GW) irrigation regimes. LSDs $(\mathrm{p}<0.05)$ indicate differences between TW and GW containers within each treatment on each day, with significant differences in bold.

\begin{tabular}{|c|c|c|c|c|c|c|c|c|c|}
\hline \multirow{3}{*}{$\begin{array}{l}\text { Time since } \\
\text { saturation }\end{array}$} & \multicolumn{9}{|c|}{ Mean cumulative water loss per container $(\mathrm{mL})$} \\
\hline & \multicolumn{3}{|c|}{ Control } & \multicolumn{3}{|c|}{ Salvia } & \multicolumn{3}{|c|}{ Heuchera } \\
\hline & TW & GW & LSD & TW & GW & LSD & TW & GW & LSD \\
\hline $24 \mathrm{~h}$ & 76 & 68 & 8.6 & 125 & 118 & 13.7 & 133 & 111 & 16.9 \\
\hline $48 \mathrm{~h}$ & 150 & 135 & 12.9 & 268 & 251 & 32.9 & 278 & 244 & 32.1 \\
\hline $72 \mathrm{~h}$ & 235 & 216 & 23.9 & 435 & 404 & 48.3 & 458 & 404 & 75.5 \\
\hline $96 \mathrm{~h}$ & 314 & 294 & 19.1 & 586 & 541 & 32.2 & 639 & 556 & 76.0 \\
\hline $120 \mathrm{~h}$ & 375 & 349 & 24.2 & 696 & 634 & 32.6 & 769 & 658 & 74.9 \\
\hline $144 \mathrm{~h}$ & 403 & 377 & 37.3 & 747 & 676 & 54.4 & 819 & 701 & 78.8 \\
\hline
\end{tabular}

Since water uptake was significantly lower from the GW irrigated control containers compared to the TW irrigated containers, evaporation from the substrate, as well as transpiration, appears to be reduced with GW irrigation. This is probably a result of GW lowering the hydraulic conductivity of the substrate (Travis et al., 2010), thus making water movement to the surface for evaporation, as well as water movement to the roots, more difficult and hence decreasing both evaporation and transpiration (Rodda et al., 2011). The volumes of water lost from the control containers each day were relatively small compared to the planted containers, and consequently impacts of GW may have taken longer to become apparent. The $g_{s}$ of TW and GW irrigated Salvia plants were similar in week 6, which may account for the similar water uptake in the first few days of drying; $g_{s}$ presumably declined in GW irrigated plants as the substrate dried out and hydraulic conductivity decreased, resulting in reduced water uptake. This indicates that as the substrate dries out, functioning of GW irrigated Salvia may become compromised, leading to lower $g_{s}$ and likely reduced provision of cooling service.

\section{CONCLUSIONS}

Results of this study showed that 6 weeks of irrigation with GW had no significant impact on the health, growth and visual quality of these four genotypes in a glasshouse study in UK summer conditions. During this period, the $g_{s}$ of these genotypes was not affected by GW irrigation, suggesting that any potential transpirational cooling service these plants could provide would likely not be compromised when plants are well-watered. However, in the $7^{\text {th }}$ week of the experiment, water uptake (ETp) was significantly lower with GW irrigation for Heuchera (whole week) and for bare substrate and Salvia after a few days of drying. This suggests that some differences between TW and GW irrigation treatments may only become apparent when SMC is depleted, and consequently GW irrigation may 
compromise the ability of some genotypes (e.g. Salvia) to continue transpiring during extended periods of drought, likely also restricting cooling. It is likely that an irrigation design alternating GW with TW may prevent accumulation of salts in the substrate, thus avoiding any negative impacts of GW on the plants' health and $g_{s}$.

\section{ACKNOWLEDGEMENT}

The authors thank Professor Čedo Maksimović and the Blue Green Dream team at Imperial College London for their constructive input. This work was funded by an EIT Climate-KIC PhD studentship.

\section{Literature cited}

Albalawneh, A., Chang, T.-K., and Chou, C.-S. (2016). Impacts on soil quality from long-term irrigation with treated greywater. Paddy and Water Environment 14 (2), 289-297.

Blanusa, T., Vaz Monteiro, M.M., Fantozzi, F., Vysini, E., Li, Y., and Cameron, R.W.F. (2013). Alternatives to Sedum on green roofs: Can broad leaf perennial plants offer better 'cooling service'? Building and Environment 59, 99106.

De Clerck, F., Singer, M.J., and Lindert, P. (2003). A 60-year history of California soil quality using paired samples. Geoderma 114 (3-4), 215-230.

Diaper, C., Toifl, M., and Storey, M. (2008). Greywater technology testing protocol (Australia: CSIRO).

Eriksson, E., Auffarth, K., Henze, M., and Ledin, A. (2002). Characteristics of grey wastewater. Urban water 4 (1), 85-104.

Eriksson, E., Baun, A., Henze, M., and Ledin, A. (2006). Phytotoxicity of grey wastewater evaluated by toxicity tests. Urban Water Journal 3 (1), 13-20.

Misra, R., Patel, J.H., and Baxi, V. (2010). Reuse potential of laundry greywater for irrigation based on growth, water and nutrient use of tomato. Journal of Hydrology 386 (1), 95-102.

Ouldboukhitine, S.-E., Spolek, G., and Belarbi, R. (2014). Impact of plants transpiration, grey and clean water irrigation on the thermal resistance of green roofs. Ecological Engineering 67, 60-66.

Pinto, U., Maheshwari, B., and Grewal, H. (2010). Effects of greywater irrigation on plant growth, water use and soil properties. Resources, Conservation and Recycling 54 (7), 429-435.

Rodda, N., Salukazana, L., Jackson, S., and Smith, M. (2011). Use of domestic greywater for small-scale irrigation of food crops: Effects on plants and soil. Physics and Chemistry of the Earth, Parts A/B/C 36 (14), 1051-1062.

Sharvelle, S., Roesner, L.A., Qian, Y., Stromberger, M., and Azar, M.N. (2012). Long-term Study on Landscape Irrigation Using Household Graywater - Experimental Study (Colorado State University, USA: Water Environment Research Foundation).

Travis, M.J., Wiel-Shafran, A., Weisbrod, N., Adar, E., and Gross, A. (2010). Greywater reuse for irrigation: Effect on soil properties. Science of the Total Environment 408 (12), 2501-2508.

Vaz Monteiro, M., Blanusa, T., Verhoef, A., Hadley, P., and Cameron, R. (2016). Relative importance of transpiration rate and leaf morphological traits for the regulation of leaf temperature. Australian Journal of Botany 64 (1), 32-44.

Vaz Monteiro, M., Blanuša, T., Verhoef, A., Richardson, M., Hadley, P., and Cameron, R.W.F. (2017). Functional green roofs: Importance of plant choice in maximising summertime environmental cooling and substrate insulation potential. Energy and Buildings 141, 56-68. 